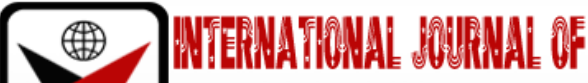

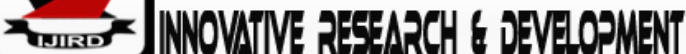

ISSN 2278-0211 (Online)

\section{An Analysis of Waterfront Development Strategy: As an Analogy of Self-Sustaining and Economically Viable City, Toronto, Canada}

\author{
Sam-Wigwe Chizindu \\ Student, Department of Architecture, Rivers State University, Nigeria \\ Paul Uchenna \\ Lecturer, Department of Architecture, Rivers State University, Nigeria \\ Daibi-Oruene Waaka Divine \\ Lecturer, Department of Architecture, \\ Kenule Beeson Saro-Wiwa Polytechnic, Nigeria
}

\begin{abstract}
:
Water as the most occurring substance on earth can be referred to as the 'elixir of life' due to its fundamental origins for human sustenance. The presence of water in various forms in its natural setting plays an important role in enhancing the quality of physical and the socio-economic environment. Moreover, presence of water bodies gives the perception of social, psychological and environment value which includes but not limited to (a) enhancing the aesthetic quality and cultural values of a place, thereby contributing to the image of the city or town, (b) enhancing the social and recreational value and thus increasing the livability of the residents and land value, (c) act as a catalyst for economic activity progression. A popular Africa proverb says 'water has no enemy' oh yes! That's true but perhaps these natural occurring or artificial waterways/bodies are being polluted by untreated waste, and in some cases, the flow is interrupted due to industrial and human activities which can lead to flooding, unhealthy environment and pose a serious health risk to both aquatic and human life. Waterfront developments are regarded as a public space, a global phenomenon influenced by different stakeholders such as government/politicians, community leaders, and individual/cooperate, investors, resident occupants if any, research institute/urban developers, architects, engineers and other building professional. This paper enlightens the reader on the key elements and themes of waterfront developments strategies, the importance and theoretical analysis of sustainable action plan/frame-work used for revitalization of Toronto waterfront development project as a case study for a self-sustaining and economically viable waterfront development project.
\end{abstract}

Keywords: Waterfront, waterfront revitalization, urban planning, Toronto, urban gentrification, sustainable policy, riverfront projects

\section{Introduction}

Before the discovery of horses, donkeys, and domestic elephants as a means of transportation, the natural waterways where used, even before the inventions of aeroplanes, ships, submarines, yachts, and speedboats, the paddle canoes were used as means of transport through different water routes connecting; which makes water as the oldest means of transportation. Water as an essential part of life, a lot of creatures with mankind as no exception, depend on water for survival. The waterfront appears to be the origin of human culture, economy and territorial autonomy. Therefore, the earliest towns and villages were close to water sources. This was not only because of our dependence on water but also due to traffic concerns. The rise and fall of many cities were related to transportation. In the very beginning, villages close to water turned into fishing villages. In the age of navigation, they became the posts of trade. In the industrial age, they became container ports. The old ports then became the new waterfront appearance. Such a process represents the diversity of waterfront use and its importance to human life and commercial activities (Chen, 2015).

The waterfront is now a magic ingredient quenching the desire of many Companies for an environmentally pleasing workplace (Warman, 1990).

Many cities are making efforts to rejuvenate the strength of their waterfront, these efforts are supported by several conditions such as the existence of slump areas and excess pollution/waste dump along the shores and riverfronts, improper allocation and use of lands, overpopulation of the main city centres and urgent need for expansion and Land left vacant by deindustrialization is now cheaper. These areas have high economic, functional and aesthetic values due to their proximity to a water body and the city core. Many different developments can be planned along the urban waterfront. Large-scale mixed-use developments offer many commercial and economic opportunities. These projects contribute a 
great deal to the process of re-establishing the vitality of the inner city. Other types of developments are more social than economic. Parks, water-edge walkways, and environmental conservation all add to the cultural landscape. Of similar importance are restorations and preservations of historical sites along the waterfront. Lastly, marketplaces, festivals, happenings and the like contribute much to an area's wellbeing. They are not only a source of economic contributions to the city, but they also enhance the culture of the area. (MANN, 1988). In most large cities of the world with waterfront developments, the following trends have been identified both as revitalization or a completely new project such as open edge and access improvements in form of promenade and boulevard, large-scale mixed-use developments, small stream and canal backside development, historic restoration and limitation, blossoming of the entire surrounding environment and market places, historic restoration and imitation, world exposition development on the waterfront, integration of environmental art and lighting, the growth of festivals and other ephemeral events, with trivial concerns on improved ecological protection and the growth of boating and other river leisure activities (MANN, 1988). Waterfront development project is the only single successful project strategy adopted worldwide that meets with all sustainable development goals for 2030 agenda and the Toronto waterfront revitalization project has proven this fact to be true. This article will review the sustainable development strategies adopted, the economic and social impact of the revitalization project to Ontario province, Toronto city and the Canadian government. This article will go a step further to enlighten the general importance of waterfront development project to attain an economically viable and self-sustaining city as well as outlining the various themes/framework for a successful waterfront development project.

\subsection{Waterfront Development}

The term 'waterfront' can sometimes be referred to as 'riverfront'. Riverfront is a region along a river. A river is a 3D space strategically located and has breadth, width and depth. In general, the waterfront is defined as a zone of interaction between urban development and an existing water body. Waterfront development is a process that begins due to the desires of a community to improve its waterfront which contains mixed-use development that is relatively consistent (Ragheb, 2017). Waterfront development varies according to the characteristics of the site and cities which are expressed as:

- Waterfront Revitalization: is growth, progress and diffusion of new economic activities into stagnant or decline cities. A rebuilding strategy based on assets: buildings (usually historic), businesses, people and organizations.

- Waterfront redevelopment: is an introduction of an entirely new programme and concept ideas which looks at land as the only valuable and present asset which needs to be cleared and redeveloped.

- Waterfront regeneration: this is a comprehensive and integrated vision and action to address urban problems through a lasting improvement in the economic, physical, social and environmental condition of an area.

- Furthermore, the basic concept of waterfront project is similar but the scale of the type varies from city to city which could be influenced by so many major and minor factors such as stakeholders' interest, finance/investors, present and future needs of the economy, cultural heritage etc. there are three main levels which help to enlighten the concept of waterfront development which are:

- Waterside development: is local and environmental planning which emphasizes the water-human relationship design and the waterfront remedy, and its objective is to create an accessible and enjoyable water environment.

- Waterfront development: is urban planning which emphasizes the feasibility study of the development projects and the spatial design, and its objective is renewal and development of the urban areas.

- Coastal development: is national planning which emphasizes the development strategies and the implementation of planning, and its objective is to prescribe the character of the city and the development scheme. (Ragheb, 2017).

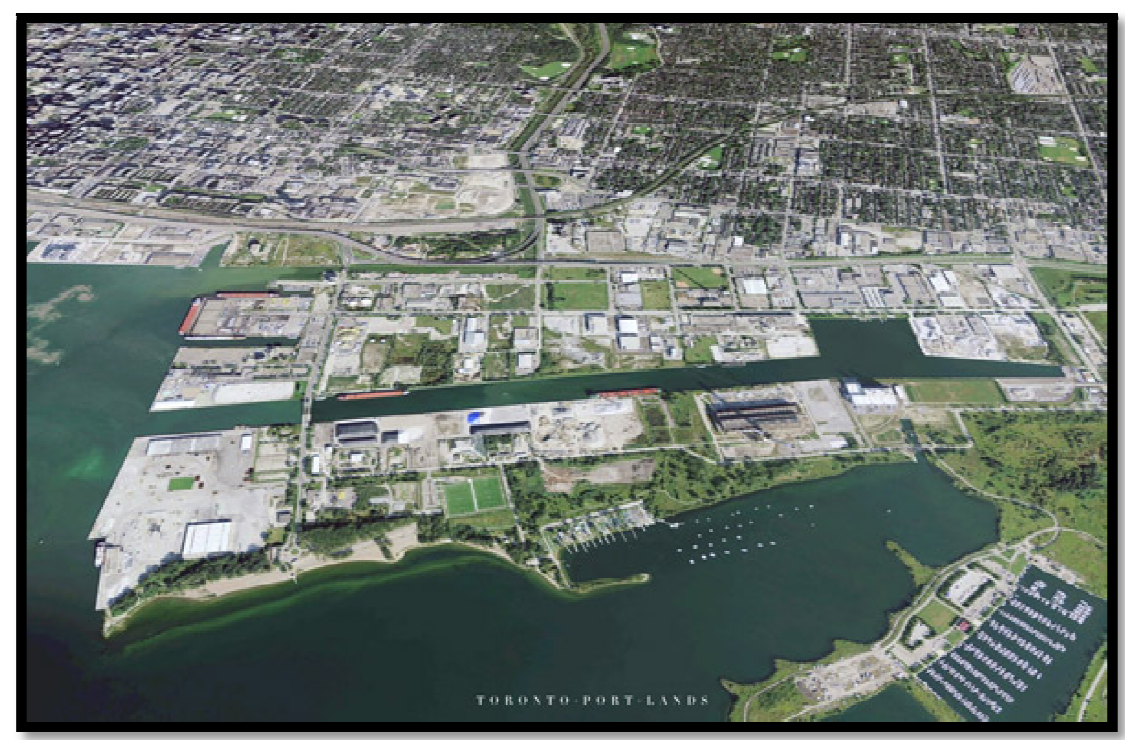

Figure 1: Showing the Ariel View of Toronto Waterfront Revitalization Project Source: Blogto 
The sustainability benefits afforded by waterfront revitalization are numerous and include:

- $\quad$ Remediating brownfields and developing new communities in the city

- $\quad$ Reducing the need to develop agricultural and environmentally sensitive land outside the city

- $\quad$ Increasing the supply of affordable housing

- $\quad$ Reducing air pollution associated with commuting

- $\quad$ Reusing or improving existing infrastructure

- $\quad$ Requiring the development of high efficiency, green buildings

- $\quad$ Making public transit, cycling and walking the primary modes of transportation

- Increasing opportunities for economic development

- Increasing the number of parks and other public spaces

- $\quad$ The increasing cultural vibrancy and beautiful public spaces.

\section{Literature Review}

Designing of cities is an attempt to make the future better than the present maybe 20-30 years from now; in terms of social, economic, and environmental aspect. The earth is a watery planet. According to the United States geological survey (USGS), about 71 per cent of the Earth's surface is water-covered, and the oceans hold about 97.2 per cent of all Earth's water. Ignoring our waterways invariable means ignoring 71 per cent of our earth in total. In the beginning, the earth was without form and void, and darkness was upon the face of the deep. According to the story of creation from the book of Genesis, And God said 'Let the waters under the heaven be gathered together unto one place, and let the dry land appear' and it was so.

The earth is a watery planet and ignoring our waterways, means denying ourselves $71 \%$ of our earth. (Sam-Wigwe et. all, 2020.)

According to the department of economic and social affairs of United Nations May 16 $6^{\text {th }} 2018$ report; $55 \%$ of the world's population live in urban areas and a proportion that is expected to increase to $68 \%$ by 2050 . Projections show that urbanization, the gradual shift in the residence of the human population from rural to urban areas, combined with the overall growth of the world's population could add another 2.5 billion people to urban areas by 2050 . The urban population of the world grew rapidly from 751 million in 1950 to 4.2 billion in 2008 . North-American is known to be the most urbanized region of the world with about $82 \%$ of its population living in the urban areas as at 2018, Latin America and Caribbean (81\%) and Oceania (68\%). The level of urbanization in Asia is now approximately 50\%. By 2030, the world is projected to have 43 megacities with more than 10 million inhabitants, most of them in developing regions. However, some of the fastest-growing urban agglomerations are cities with fewer than 1 million inhabitants, many of them located in Asia and Africa. While one in eight people live in 33 megacities worldwide, close to half of the world's urban dwellers reside in much smaller settlements with fewer than 500,00 inhabitants. Sustainable urbanization is the key to the successful development and understanding the key trends in urbanization likely to unfold over the coming years is crucial to the implementation of the 2030 Agenda for sustainable development. (United Nations, 2018). Toronto was designated the capital city of Ontario province in 1867 during the Canadian confederation; the most populous city located in Canada (North-America) with a population of $2,731,51$ as of 2016 . Shifts in government responses to civil society and private sector's interest; the most recent phase of development marks a new period of change on Toronto's central waterfront through the integration of a sustainability agenda into the planning, design, and redevelopment processes. Since 2004, a broad concept of sustainability was defined through policies and strategies for residential and commercial redevelopment put forward by the Toronto waterfront revitalization corporation (TWRC), a publicly legislated and funded urban development corporation. (Bunce, 2009). Waterfront Toronto revitalization cooperation with its primary objective of waterfront revitalization is to leverage the infrastructure project to deliver key economic and social benefits that enables Toronto to compete aggressively with other top tier global cities for investment, jobs and people by bringing the most innovative approaches to sustainable development, excellence in urban design, real estate development, and advanced technology infrastructure. It is one of the largest infrastructure projects in North-America and one of the largest waterfront redevelopment initiatives ever undertaken in the world. However, it is not just the sheer scale that makes it unique; waterfront Toronto is a delivery leading-edge city-building model that seeks to place Toronto at the forefront of global cities index in the $21^{\text {st }}$ century. 


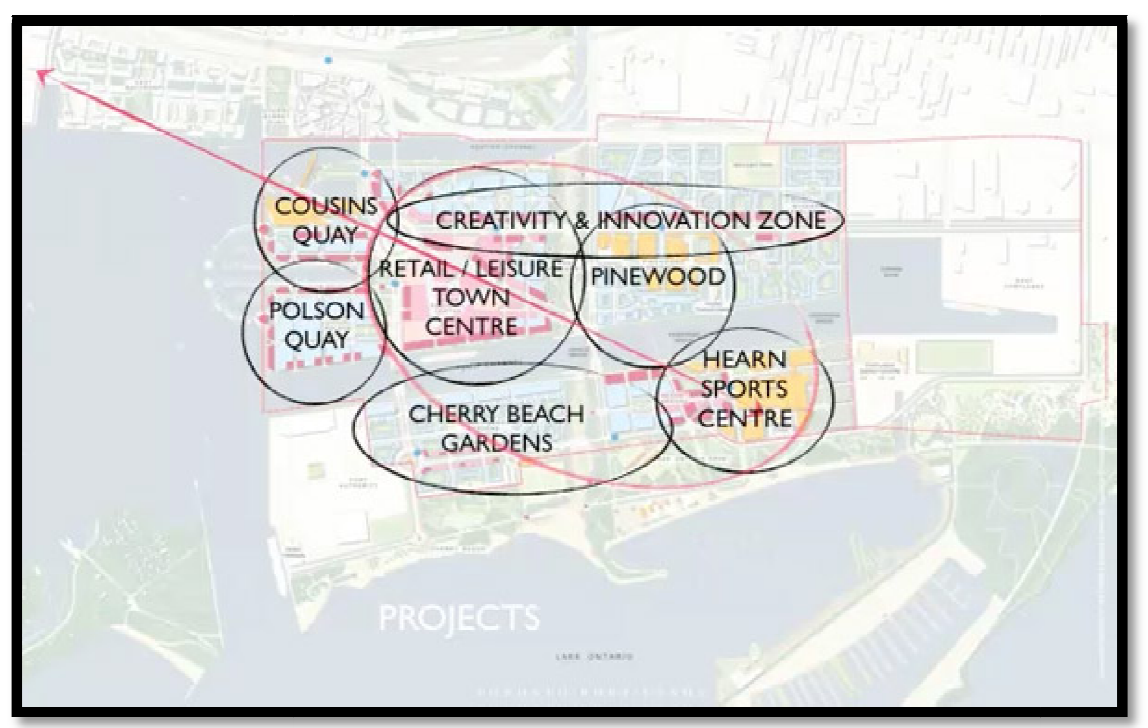

Figure 2: Showing Zoning of Toronto Portland Project

Source: Urban Metrics, 2014

\subsection{The City as an Aesthetic Object}

The city should be able to provide a site for performative art: lifestyle, rituals, and cultural traditions. Looking at cities can give a special pleasure, however, commonplace the sight may be. Like a piece of architecture, the city is a construction in space, but one of vast scale, a thing perceived only in the course of long periods. At every instant, there is more than the eye can see, more than the ear can hear, a setting or a view waiting to be explored. Nothing is experienced by itself, but always concerning its surroundings, the sequences of events leading up to it, the memory of past experiences. Washington Street set in a farmer's field might look like the shopping street in the heart of Boston, and yet it would seem utterly different. Every citizen has had long associations with some part of his city, and his image is soaked in memories and meanings. Nearly every sense is in operation, and the image is the composite of them all. Not only is the city an object which is perceived (and perhaps enjoyed) by millions of people of widely diverse class and character, but it is the product of many builders who are constantly modifying the structure for reasons of their own. While it may be stable in general outlines for some time, it is ever-changing in detail. Only partial control can be exercised over its growth and form. There is no final result, only a continuous succession of phases. A vivid and integrated physical setting, capable of producing a sharp image, plays a social role as well, it can furnish the raw material for the symbols and collective memories of group communication. A good environmental image gives its possessor an important sense of emotional security. He can establish a harmonious relationship between himself and the outside world. (Lynch, 1990). The image of the city and the memory it creates on the dwellers or visitors depends on the 'form' which could be influenced by natural occurrence and human activities. Mr Kelvin Lynch formulates a new criterion 'Imageability' and shows its potential value as a guild for the building and rebuilding of cities through a careful study of three cities: Los Angeles, Boston, and Jersey City. The following are the elements that influence the image of the city:

- Paths

- Edges

- Districts

- Nodes

- Landmarks

Mr Kelvin Lynch further disclosed that this analysis limits itself to the effects of physical, perceptible objects. There are other influences on 'imageability', such as the social meaning of an area, its function, its history, or even its name

\section{The Case of Toronto Waterfront Revitalization Project}

On October 20,2000, the Government of Canada, the Province of Ontario, and the City of Toronto each announced a commitment of $\$ 500$ million to fund the TWRI. To this end, the Toronto Waterfront Revitalization Corporation (TWRC), a not-for-profit corporation, was established on November 1, 2001, to lead the waterfront renewal. Also, the Government of Canada created a federal Toronto waterfront revitalization initiative (TWRI) secretariat to oversee the federal contribution and the TWRC on its behalf. Public accessibility, design excellence, sustainable development, economic development and fiscal sustainability are the key drivers of waterfront revitalization. The Toronto Waterfront Revitalization Corporation (now known as Waterfront Toronto) is a quasi-autonomous agency that was created in 2001 by the three levels of government- local, provincial and federal. They came together to develop Toronto's vast, underutilized waterfront. In the 1980s huge parcels of land were sold to private developers resulting in the fragmentation of the waterfront. However, in 1992, the Royal Commission on the future of the Toronto Waterfront released a wide-ranging report that focused on sustainability and supported mixed-use redevelopment and improved public access to the waterfront. These led to attempts to create a cohesive, unbroken waterfront for the provincial capital of Ontario. Toronto aspiration to host the Olympic games of 2008 which led to an unsuccessful bid was the catalyst for improved urban planning and affordable housing for Torontonians. (epavan, 2013). Waterfront Toronto has a 25-year mandate to 
transform 800 hectares (2,000 acres) of brown field lands on Toronto's waterfront into beautiful, sustainable mixed-use communities and dynamic public spaces. Resulting visions for the design proposal included:

- Connecting the city of Toronto with Lake Ontario

- Creating special places where the city meets the lake

- Intimate activity and scale by the waterfront

- Restore the mouth of the Don River

- Preserving industrial heritage

- Creating major public plazas and open spaces

- Continuous waterfront access

- Building on Toronto's typical block pattern (Toronto Waterfront Revitalization Corporation, 2002)

These are some of the schemes under the Toronto Waterfront Revitalization project:

- Villiers Island Precinct Plan (2014-Present)

- $\quad$ Port Lands Acceleration Initiative (2011-2012)

- Public Spaces Frameworks and Parks (2000- Present)

- West Don Lands Revitalization (2003-2007)

- $\quad$ East Bayfront Precinct Planning and Implementation (2005- Present) (Urban Strategies Inc, 2000)

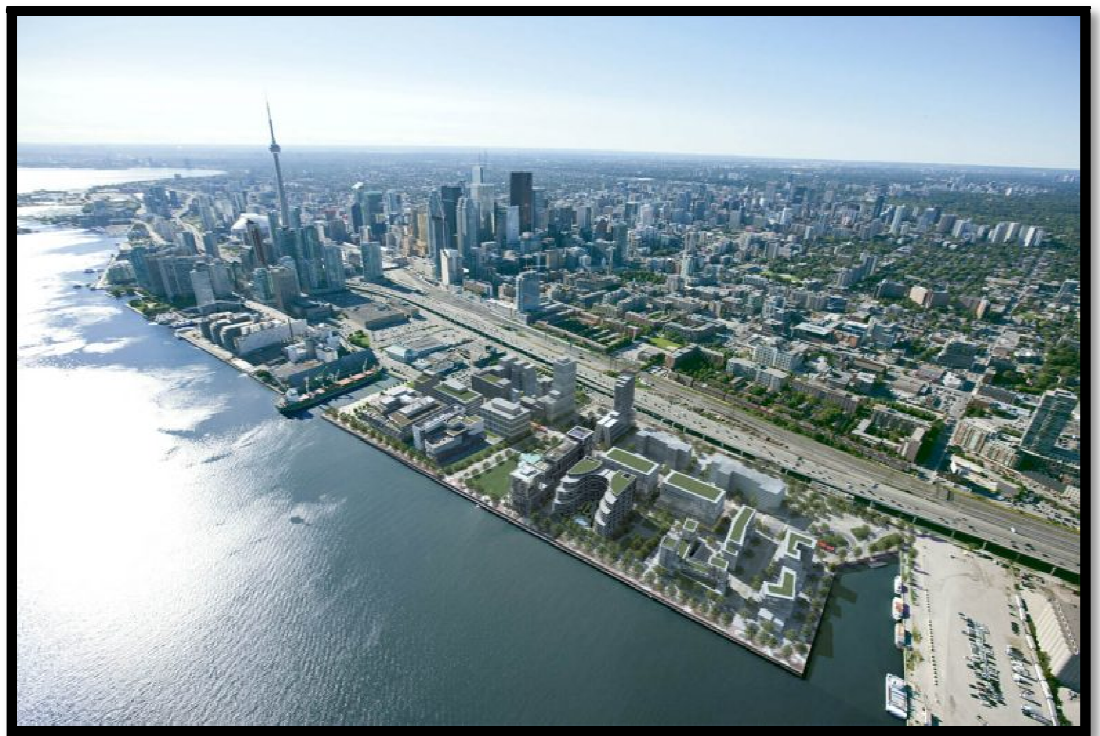

Figure 3: 25,000 Sq. Foot Community Centre Built at 261 Queens Quay E. Located at the Base of Tridel's and Hines' Bayside Development Credits: Waterfront Toronto

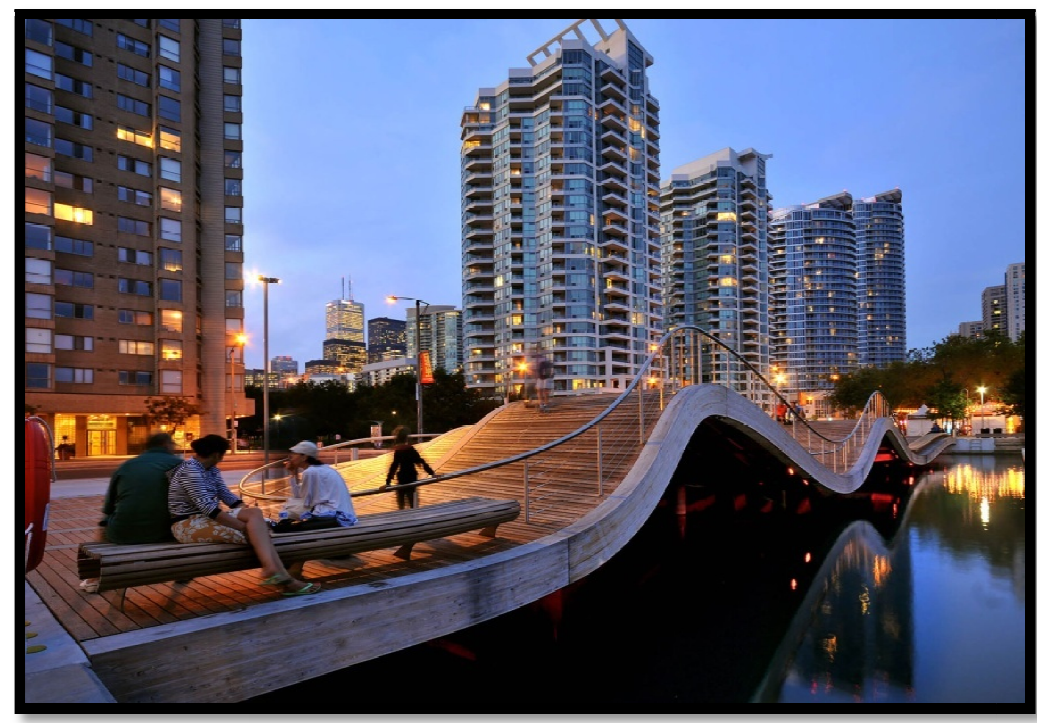

Figure 4: The Simcoe Wavedeck Next to the Martin Goodman Trail and Queens Quay Boulevard. Credit: Waterfront Toronto

\subsection{Sustainable Action Plan/Framework of Toronto Waterfront Revitalization Cooperation (Twrc)}

Waterfront Toronto's revitalization mandate has an emphasis on global best practices in sustainable development, including district energy, green buildings, and a risk-managed approach to the redevelopment of this brownfield area. 


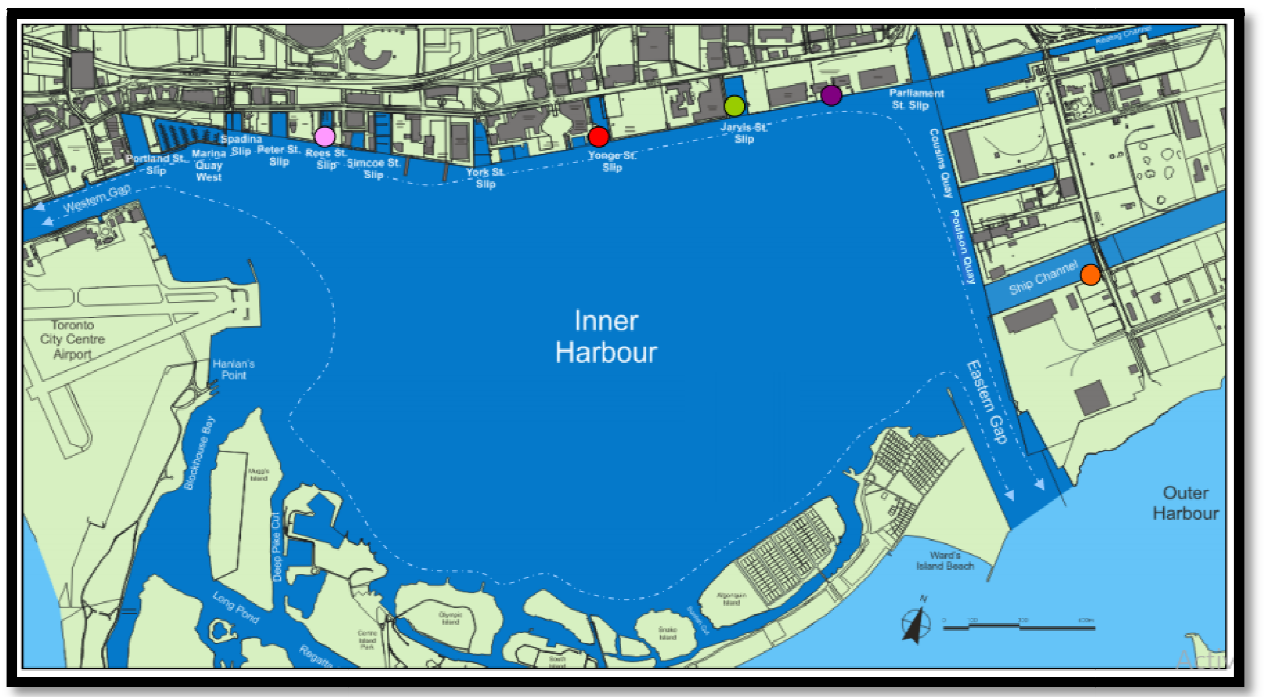

Figure 5: Masterplan of Inner Harbour Toronto Waterfront Revitalization. ((TWRC), 2006)

Urban Strategies work on the development plan for the waterfront included a Sustainable Development Framework, which reflects our firm's approach to sustainable planning and design. Guided by, and ultimately reflecting the goals of the world's leading green building systems, including BREEAM and LEED, our frameworks featured district energy and passive energy in power park utilities; walkable and transit serviced communities; reduced right-of-ways to maximize green spaces; sustainable planting; and design practices such as permeable parking surfaces.

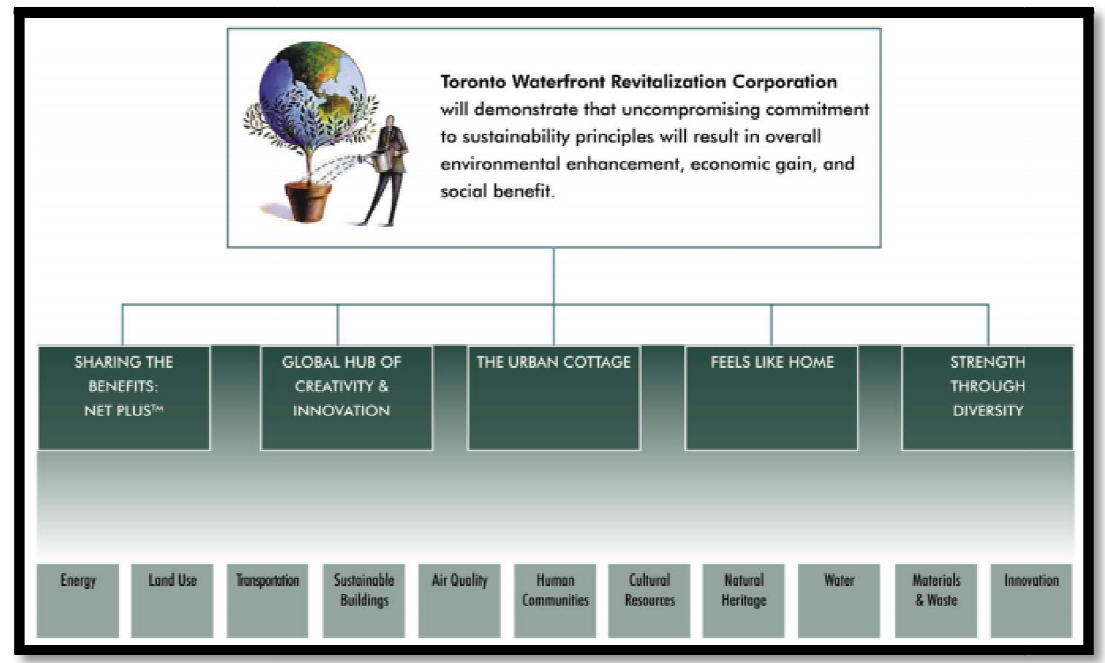

Figure 6: Shows the Toronto Waterfront Development Cooperation Sustainability Framework

\subsubsection{Energy}

\subsubsection{Goals}

Significantly reduced levels of per capita energy consumption coupled with greater use of low-impact renewable energy to meet energy demands

\subsubsection{Objective}

- High levels of energy efficiency

- Increase the percentage of energy consumption from renewable sources

\subsubsection{Strategy}

Energy efficiency measures during site and infrastructure planning, building retrofit, design and operation. Reliance on renewable energy sources that have low impacts on air pollution and global warming and that increase energy self-sufficiency thus reducing pressure on the provincial grid.

\subsubsection{Action plan}

- Design buildings with high levels of energy efficiency (links to the action on LEED Gold and Platinum standards).

- Land use planning based on mixed land use and a compact development form to hold the energy profile at a close to steady-state despite increased development and to reduce energy needs. 
- Make use of a district energy system (or systems) that relies on a local energy producer to generate and distribute electricity, heating, and cooling. The proximity of producer and consumer dramatically decreases the amount of electricity lost over transmission lines and allows otherwise wasted heat to be shared with adjoining buildings.

- Compile an inventory of financial incentives for builders and owners, including rebates, matching funding, funds for pilot projects and tax incentives associated with energy efficiency initiatives

\subsubsection{Land Use}

3.1.2.1. Goals

Land use planning that supports sustainable community development.

3.1.2.2. Objective

- Mixed land use

- Vibrant street life.

- Enhanced animal and aquatic habitat

\subsubsection{Strategy}

- Designate car-free zones.

- Attract people to the streets.

\subsubsection{Action Plan}

- Habitat enhancement along the water's edge - including harder edge on the western side and more wetland - as on the east.

- Infrastructure creation that facilitates understanding, appreciation, and use of fish and wildlife resources.

- Orient building and streets to optimize access to natural lighting and heat from the winter sun.

- Install three to four kilometres of well-designed walkways that are attractive and functional throughout all four seasons, regardless of climate

- Orient buildings and streets to ensure most walking zones have good sunlight for a significant part of the day.

\subsubsection{Transportation}

\subsubsection{Goals}

Make alternative transportation options such as walking cycling and public transit the natural choice for residents and visitors to the waterfront area.

\subsubsection{Objective}

- Minimize car use

- Increase walking cycling and public transit use

\subsubsection{Strategy}

- $\quad$ Mixed-use planning to minimize car use.

- $\quad$ Make walking, cycling and public transit attractive options.

\subsubsection{Action Plan}

- Designate car-free zones.

- $\quad$ Situate basic shopping needs and personal services within walking distance of residential units.

- $\quad$ Minimize the amount of impervious paved surfaces for roads and parking.

\subsubsection{Sustainable Buildings}

\subsubsection{Goal}

Elegant architectural building systems that reduce negative environmental impacts and provide high indoor air quality and exceptional comfort.

\subsubsection{Objective}

- High-performance sustainable building systems.

- Building sites that maximize sustainability opportunities.

- Buildings that are compatible with a high quality of life in associated communities.

3.1.4.3. Strategy

- $\quad$ Showcase sustainability buildings of outstanding beauty and high performance.

- Integrated design process.

- $\quad$ Apply LEED standards. 
- $\quad$ Buildings that allow residents, workers, and visitors to the waterfront to feel connected to nature.

- $\quad$ Super-size the height of the first floor of residential buildings to allow for easier conversion to commercial uses over time.

\subsubsection{Action Plan}

- Produce marketing materials aimed at the development community and the general public outlining the benefits of sustainable buildings.

- Develop an awards program that recognizes excellence in sustainable building design on the Toronto waterfront.

- Build an exemplary sustainability building or set of buildings very early in the waterfront revitalization process.

- Hold integrated design workshops with members of the design, construction, and operations teams at the beginning of all major building initiatives.

- Explore the opportunities for different types of district heating and cooling, capitalizing on economies of scale and long-term financial arrangements.

\subsubsection{Air Quality}

Goal: Minimize pollutant emissions on the Toronto waterfront to help improve air quality in the City and throughout the region.

\subsubsection{Objectives}

- Reduce concentrations of the air pollutants that contribute to smog.

- Minimize dust from construction and demolition activities.

- Purify the air and add beauty and comfort on site

\subsubsection{Strategy}

- Adopt a set of demolition and construction dust control protocols for the Toronto waterfront.

- $\quad$ Expand tree canopy

- $\quad$ Mixed-use planning to minimize car use.

\subsubsection{Action Plan}

- Situate basic shopping needs and personal services within walking distance of residential units.

- Adopt a set of demolition and construction dust control protocols for the Toronto waterfront.

- Develop a landscaping plan to provide shade in summer and wind resistance in winter

- Develop tree maintenance protocols to ensure sustained tree growth.

\subsubsection{Human Communities}

\subsubsection{Goal}

Vibrant welcoming healthy and inclusive waterfront communities

\subsubsection{Objective}

- Waterfront communities that attract people year-round

- A place to live for people from all walks of life throughout the life cycle

- The appropriate mix of residential and commercial space

- Community involvement in growing healthy nutritious food.

\subsubsection{Strategy}

- Enhanced recreational features.

- A diverse housing mix and related community services.

- Draw small, medium, and large businesses to the waterfront.

- Community gardening

\subsubsection{Action Plan}

- Create and maintain a green and open space that is suitable for a wide range of recreational activities and parkland.

- Develop winter recreational programs across the Toronto waterfront.

- Include appropriate housing to support all age groups and families of all types, sizes, and economic levels.

- Build or enhance the appropriate number and type of community services including outdoor play areas, community centres, elementary and secondary schools, daycares, and libraries.

- Encourage organic farming/gardening methods. 


\subsubsection{Cultural Resources}

3.1.7.1. Goal

A high level of cultural vibrancy and creativity

\subsubsection{Objectives}

- Maximize cultural resources on the waterfront

- Protect and enhance existing cultural and heritage resources, including built heritage

- Maximize cultural activities

\subsubsection{Strategy}

- Incorporate cultural features and activities throughout the waterfront

- Understand the nature and extent of existing waterfront built and cultural heritage and archaeological resources and how they can be integrated as part of sustainable community development.

- $\quad$ Provide a wide range of opportunities for cultural activities and facilities.

3.1.7.4. Action Plan

- Create a visual identity program including public art and interpretive resources.

- Create cultural and heritage destinations on a variety of scales.

- Strengthen connections between the waterfront and the city through historically and/or culturally significant corridors.

- Support artistic and cultural expression in new buildings, new infrastructure, in urban ecological processes and green and open spaces.

- Develop an operational strategy for integrating cultural heritage resources into planning and design for site, buildings and infrastructure using approaches such as restoration, adaptive re-use and public art.

\subsubsection{Natural Heritage}

3.1.8.1. Goal

Greatly enhance the environmental integrity of the Toronto waterfront

\subsubsection{Objectives}

- Extensive habitat improvement

- $\quad$ Strengthen native biodiversity

- State-of-the-art integrated soil management

\subsubsection{Strategy}

- $\quad$ Restore and enhance natural communities following soil, topographic and hydrologic conditions.

- Ground cover with a diversity of indigenous plant species.

- Safe and effective management of contaminated soils.

\subsubsection{Action Plan}

- Implement the recommendations for improving the ecological health of the shoreline contained in the Toronto Waterfront Aquatic Habitat Restoration Strategy (TWARHS) including improving water and sediment quality, reintroducing top predators such as muskellunge and walleye and increasing structural diversity across the waterfront.

- $\quad$ Protect and restore the habitat for all wildlife, including migratory birds.

- Create and maintain networks of green space throughout the waterfront as identified in the Toronto and Region Terrestrial Natural Heritage System Strategy (TNHSS)

- Identify native plants most suitable for waterfront revitalization.

- Implement the TWRC's Integrated Groundwater Management Soil Strategy.

\subsubsection{Water}

3.1.9.1. Goal

Improve water quality along the Toronto waterfront and reduce per capita consumption of freshwater.

\subsubsection{Objectives}

- Contribute to improved water quality in the lake

- Protect groundwater from contamination

- $\quad$ Reduce the use of potable water

- Celebrate the waterfront setting and water as a feature 


\subsubsection{Strategy}

- $\quad$ Reduce the likelihood of contaminants entering the lake.

- Increase the use of rainwater and greywater.

- Encourage artistic expression using water as the theme and incorporate art as an integral part of building sustainability components.

\subsubsection{Action Plan}

- Implement measures help absorb rainwater such green roofs, widespread greenspace, permeable surfaces, rain gardens, and, where necessary, surface gutters routing water to rain gardens.

- Institute best practice guidelines for the control of herbicides; salt; animal waste and other pollutants.

- Reduce the quantity and improve the quality of stormwater runoff by implementing the recommendations of the City of Toronto Wet Weather Flow Management Master Plan (WWFMMP).

- Design and implement an integrated water management plan that relies on the use of clean stormwater

- Design and install distinctive pieces of water art along the waterfront.

\section{$\underline{\text { 3.1.10. Material and Waste }}$}

\subsubsection{Goal}

Significantly reduce per capita waste production over current levels and minimize the use of resources for the production of building and other materials.

\subsubsection{Objectives}

- Waste reduction

- Re-use and recycling

- Local economic development

- On-site containment of waste

- Avoid the use of materials and compounds that create health or environmental risks during production, use or disposal

\subsubsection{Strategy}

- $\quad$ Set per capita waste reduction targets.

- Choose salvaged or recycled materials over new ones, and re-use building components and existing systems where safety and suitability permit.

- Buy from local suppliers.

- Minimize the use or production of hazardous waste during revitalization activities.

\subsubsection{Action plan}

- Provide area residents with information on waste reduction strategies.

- Implement the TWRC's construction and demolition materials management strategy.

- Establish a temporary on-site recycling facility to handle construction materials. Include opportunities for the public to purchase materials not needed for construction.

- Establish a facility for on-site composting of organic waste

- Produce an information guide on product substitution of non-hazardous products for hazardous materials.

- Conduct an annual hazardous waste audit to evaluate hazardous waste levels and find new opportunities for substitutions.

\subsubsection{Innovation}

3.1.11.1. Goal

To encourage innovation as a means to make the Toronto Waterfront the foremost example of sustainability and a centre for creativity and knowledge.

\subsubsection{Objectives}

- Stimulate creativity and innovation

- Bring attention to Toronto waterfront's sustainability achievements and potential

- Ability to accommodate important technological advances

\subsubsection{Strategy}

- Incentives to be innovative.

- Promotion of the Toronto waterfront as a centre for innovation and creativity.

- Flexibility platforms in new buildings and infrastructure 


\subsubsection{Action Plan}

- Establish a waterfront "innovation in sustainability" recognition program.

- Begin compiling an inventory of all innovative activities on the waterfront in 2004. Document with photographs and video and promote at local, national and international events.

- Hold a biennial international conference and exhibition on innovation in sustainability.

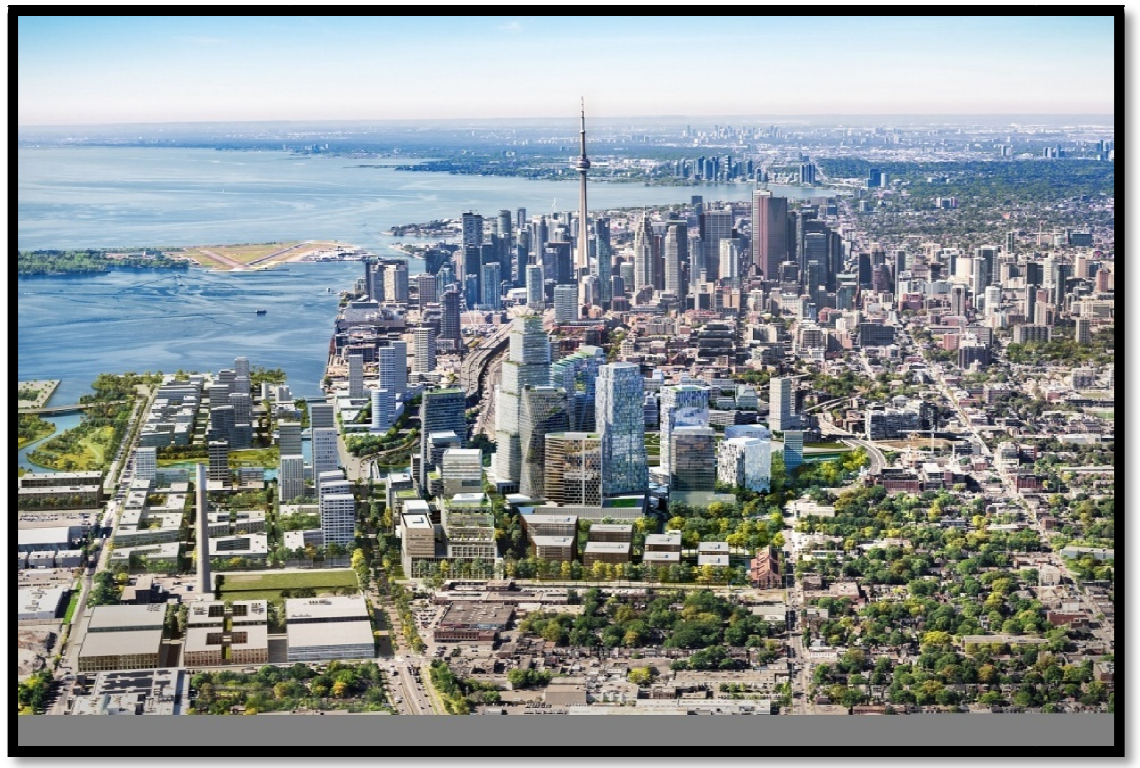

Figure 7: Aerial View Facing East Over East Harbour, Image Courtesy CNW Group/Cadillac Fairview Corporation Limited

\subsection{Economic Impact of Toronto Waterfront Revitalization Project}

The revitalization of the Toronto's waterfront will add several amenities: cultural, entertainment and recreational facilities, park, live-work neighbourhoods; which in turn will make the City a more desirable place to live and work and, by extension, conduct business. (TWRC Development Plan and Business Strategy 2003.). A total of 5,000 trees, 2million plants and 77,000 shrubs have been planted, 2 new fish coves and 1 million litres of storm water captured per month as part of the sustainable development strategy. To date, waterfront neighbourhoods have attracted more than $\$ 10$ billion in private sector investment. In 2019-2020, private firms invested $\$ 3.2$ billion in residences and workplaces in the growing communities along the lake. In 2012, the project won the world's most prestigious environmental awards 'Globe Award for Environmental Excellence in Urban Sustainability'. In 2007, 'Aqualina at Bayside became first Canada's LEED Platinum residential building. The West Don Lands welcomes Corktown Common, Canada's first organically managed park: designed to promote biodiversity, and maintained without pesticides or herbicides in 2014. Villiers Island one of the first climate positive neighbourhoods in the world launched in 2020. A total investment of \$175.4 million in the Port Lands Flood Protection Project in 2019/2020, a significant share of the $\$ 311$ million total invested to date. The Port Lands Flood Protection Project will unlock the development potential of 240 hectares of land by 2024. Representing 290 hectares in all, the Port Lands includes more than a third of the entire waterfront revitalization area. Considering both direct construction activity at the site and the subsequent realization of the development potential of the area, this project is expected to generate: $\$ 1.9 \mathrm{~B}$ in government revenue, $\$ 5.1 \mathrm{~B}$ in overall value to the Canadian economy. Toronto Waterfront Revitalization project has won 104 design awards and created 2,047 full-time employment jobs with labour income of $\$ 175.3$ million, \$82.1 million tax contribution, 3500 residential units and GDP \$238.8 million. (waterfront Toronto, 2020)

\section{Conclusion}

Sustainability is a process that continues to adjust to changing realities. Revitalizing Toronto's waterfront is an ideal opportunity to re-establish meaningful relationships with the waterfront parcels of land and Lake Ontario. To transform underutilized lands into vibrant and inclusive public and cultural spaces for all Torontonians is the epitome of multi-faceted place making. Once thought of as almost quixotic, the waterfront of Toronto has shown how intervention on the urban scale can wholly transform a city. Through the success of the Toronto Waterfront and the economic impact, the Canadian government has proven that reviving or developing the waterways is a good approach towards attaining a sustainable and economically viable city.

\section{Recommendation}

In 2017, a protest 'Let's Not Drown Belgrade' was carried out by the residence of Belgrade. There are many reasons for rage, protest and objections. Mainly because of the way the development is being carried out: Families have been moved out of their homes to make space for the new development. Legal and planning documents have been changed according to the needs of the political and financial decision-makers. Local institutions or professionals did not influence the project. As a result, faceless architecture is meeting a historic city. There is no transparency about financial backing. Apartments will not be available for average citizens (Guiding Architects, 2020). The experiences gotten from Belgrade 
waterfront development project, Serbia, is a fact that waterfront development should not just be of political or private investor's interest, but careful involvement of all stakeholders. Toronto waterfront development was able to solve the housing needs of every one according to income level and class by providing housing units of different cost and sizes to enable those displaced due to revitalization purchase back better apartments and still maintain their historic lands.

\section{References}

i. (TWRC), T. w. (2006). Marine use strategy. Toronto: Toronto waterfront revitalization cooperation (TWRC). Retrieved October 11, 2020, from https://waterfrontoronto.ca/nbe/wcm/connect/waterfront/e143aaca1997-46c8-844d-a8215f6d7d2d/4521de3b5013c.pdf?MOD=AJPERES

ii. Bunce, S. (2009). Sustainability: sustainability policy and gentrification on Toronto's waterfront. Local environment.

iii. Campbell, J. W. (2005). Message from the President and CEO: Toronto: Toronto waterfront revitalization cooperation (TWRC).

iv. Chen, D. C.-H. (2015). The Interrelationship between Waterfront Development Units. Global Journal of Science Frontier Research: E Interdisciplinary, 15(3), 9. Retrieved September 30, 2020, from https://globaljournals.org/GJSFR_Volume15/2-The-Interrelationship-between-Waterfront.pdf

v. epavan. (2013, January 29). Toronto Waterfront Revitalization: A Case Study. Retrieved from Medium: https://medium.com/@eshapavan26/toronto-waterfront-revitalization-a-case-study-15b5040a0b9d

vi. Gileno, S. (2013). Government investments in Toronto's. Toronto: Toronto Waterfront Revitalization Cooperation (TWRC).

vii. Guiding Architects. (2020, January 24). An Update of the Belgrade Waterfront Project. Retrieved from Guiding Architects: https://www.guiding-architects.net/update-belgrade-waterfront-project/

viii. Lynch, K. (1990). The image of the city. Massachusetts: Twentieth Primetime.

ix. MANN, R. B. (1988). Ten trends in the continuing renaissance of urban waterfronts. Landscape and urban planning, 16(1-2), 177-199. DOI:10.1016/0169-2046(88)90042-4

x. Ragheb, R. A. (2017). Sustainable Waterfront Development-A Case Study of Bahary in Alexandria, Egypt. Journal of Civil Engineering and Architecture, 380-394.

xi. $\quad$ smart growth network. (2009.). Smart Growth for Coastal \& Waterfront Communities. silver spring.: National Oceanic and atmospheric administration. Retrieved August 8, 2020, from

https://coastalsmartgrowth.noaa.gov/smartgrowth_fullreport.pdf

xii. United nations. (2018, May 16). News: department of economic and social affairs. Retrieved October 10, 2020, from united nations: https://www.un.org/development/desa/en/news/population/2018-revision-of-worldurbanization-prospects.html

xiii. Urban strategies inc. (2013, May 05). Toronto waterfront revitalization. Retrieved from urban strategies: https://www.urbanstrategies.com/project/toronto-waterfront-revitalization/

xiv. waterfront Toronto. (2020). Resilient Toronto, Resilient Waterfront: integrated annual report. Toronto: waterfront Toronto. 